\title{
Stability Assessment of Deep Three-Soft Outburst Coal Seam Roof Based on Fuzzy Analytic Hierarchy Process
}

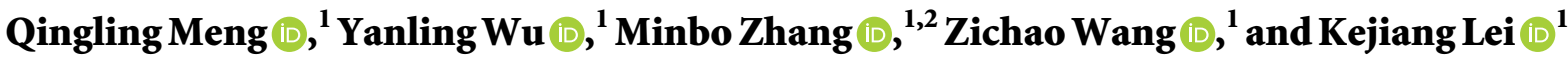 \\ ${ }^{1}$ School of Xingfa Mineral Engineering, Wuhan Institute of Technology, Wuhan 430073, China \\ ${ }^{2}$ Jizhong Energy Resources Co., Ltd., Xingtai 054000, China \\ Correspondence should be addressed to Yanling Wu; 04001073@wit.edu.cn and Minbo Zhang; zhangminbo2015@163.com
}

Received 13 April 2021; Accepted 7 May 2021; Published 20 May 2021

Academic Editor: Haiyan Wang

Copyright $(2021$ Qingling Meng et al. This is an open access article distributed under the Creative Commons Attribution License, which permits unrestricted use, distribution, and reproduction in any medium, provided the original work is properly cited.

The stability of deep "three-soft" coal seam roof has always been a key issue in coal mining. There are a lot of factors affecting the stability of deep three-soft coal seam outburst roof. However, there is currently no definite method able to draw an accurate assessment conclusion on roof stability. In order to accurately determine the main influencing factors of the stability of deep threesoft coal seam outburst roof and reduce the loss of coal production, this paper performed three-soft coal seam risk identification on Lugou Mine based on the introduction of the fuzzy analytic hierarchy process theory. 23 main risk factors were identified. Then, it established a hierarchical structure model of coal seam roof stability in accordance with experts' opinions. The analytic hierarchy process was used to calculate the weights of indicators at all levels. Next, the paper used the fuzzy comprehensive evaluation method and expert scoring to evaluate various risk factors in the indicator system, as well as the overall safety level. The results showed that the deep three-soft coal seam stability of Lugou Mine ranks the third hazard level. The main risk and harmful factors include safety awareness, safety monitoring system, roof weakness, ventilation system, fire-fighting system, and rock bolt quality. In response to the evaluation results, this paper formulated corresponding control measure in terms of ventilation risk, safety monitoring risks, construction personnel risks, and fire protection risk to reduce losses in the mining process, providing a new evaluation method for the stability assessment of deep outburst coal seam roof.

\section{Introduction}

China is a country with a huge coal resource storage. The total proven coal reserves are 5.57 trillion tons, ranking first in the world. In recent years, with the rapid development of the social economy, the demand for energy has increased in China [1]. Coal has always been one of China's main energy sources. About $70 \%$ of China's energy comes from coal. Coal and gas outburst has always been a major disaster plaguing China's efficient and safe production of coal mines [2-4]. Coal and gas outburst accidents occur every year in China. The causes are diverse. Due to these characteristics, "three-soft" coal seams are prone to coal and gas outburst accidents [5]. "Three-soft" coal seams refer to soft roof and floor stratum, soft main coal seams, and soft seam floor stratum encountered in coal mining. In general, the coal seam and roof and floor with three soft features are weak strata, the coal seam fracture is developed, and the structure is complex $[6,7]$. The strength of "three-soft" coal seams is very low. For this reason, the thickness of coal seams during mining operation varies greatly. The coal body is mostly scaly or powdery, resulting in unstable gas conditions. It is prone to gas outburst accidents, greatly affecting normal tunneling work [8-10].

At present, there is not much analysis of the stability of three-soft coal seam outburst roof. Coal seams are just evaluated by a single qualitative or quantitative evaluation method. The analysis results often have large errors. The fuzzy analytic hierarchy process combines qualitative and quantitative methods, making evaluation results more reasonable and scientific. Laarhoven and Pedrycz [11] first proposed a comprehensive evaluation method combining the fuzzy mathematics theory and the analytic hierarchy process. Chen and Wu [12] applied the fuzzy analytic hierarchy process to $3 \mathrm{D}$ printer performance evaluations and 
proposed the fuzzy collaborative intelligent analytic hierarchy process. Wang et al. [13] used the fuzzy analytic hierarchy process to determine optimal stope structure parameters. In order to overcome the subjectivity and unity of traditional evaluation methods, Song et al. [14] put forward a new method of using the fuzzy analytic hierarchy process to select coal mining methods. Sridhar and Ganapuram [15] used the fuzzy analytic hierarchy process to analyze the factors affecting the maintenance function on a more sustainable manufacturing process. Peyman et al. [16] created an earthquake risk assessment (ERA) diagram for Sanandaj, Iran, through the fuzzy analysis analytic hierarchy process. Zhou et al. [17] conducted the fuzzy comprehensive evaluation on the stability of bedding slopes reinforced by prestressed anchor cables. The evaluation results obtained were consistent with the on-site monitoring results. Ince et al. [18] used the fuzzy analytic hierarchy process to determine metrics related to the sustainable performance in the construction industry. Mallick et al. $[19,20]$ used FAHP and MCDM technologies, together with the geographic information technology, to perform a weighted overlay analysis of the groundwater potential area of the ItwadKhamis watershed in Saudi Arabia. Rouyendegh et al. [21] used FAHP to construct a decision-making model to improve the operating performance of healthcare companies. Wijitkosum and Sriburi [22] used FAHP to analyze and assess the desertification risk in the upper reaches of the Bicebri River. Wang et al. [23] established a targeted groundwater environmental impact assessment indicator system specifically and determined the weight of each index, as well as the impact level through the fuzzy comprehensive analytic hierarchy process. Zhang et al. [24] applied FAHP to flood control and discharge to solve flood discharge conflicts between different areas within watershed when floods occur. Riibas et al. [25] used the fuzzy analytic hierarchy process (FAHP) to evaluate the project risk of a large hydropower project in the construction stage. Wu et al. used FAHP in the PBA construction risk analysis of subway stations [26]. Liang studied the highway cost risk assessment based on the fuzzy analytic hierarchy process [27]. Li optimized the mining method of the manganese mining area based on the fuzzy analytic hierarchy process [28].

On the basis of the above analysis, although scholars at home and abroad had applied the fuzzy analytic hierarchy process to many aspects, no one has analyzed the stability of deep three-soft coal seam roof in coal mines. Fuzzy mathematics can be used for qualitative analysis. The analytic hierarchy process can solve problems quantitatively. The fuzzy analytic hierarchy process combines the qualitative and quantitative analyses to make results more scientific and reasonable.

\section{Theoretical Basis}

2.1. Fuzzy Analytic Hierarchy Process. The fuzzy analytic hierarchy process is a systematic analysis method combining qualitative and quantitative analysis. It is a comprehensive application of the analytic hierarchy process and the fuzzy evaluation method [29]. The essence of the analytic hierarchy process is a way of decision-making thinking. First, a complex problem is considered as a system. The system is decomposed into multiple small aspects. Then, each small aspect is decomposed to establish a hierarchical structure model, which is generally divided into three layers from high to low: target layer, criterion layer, and scheme layer. The relative importance of each two factors in each level will be compared to calculate the weight of each factor in the evaluation system [30]. The fuzzy comprehensive evaluation method aims to transform qualitative evaluation into quantitative evaluation. Its basic idea is to apply the fuzzy transformation principle and the maximum membership principle to consider the comprehensive evaluation of all factors related to the item to be evaluated. The focus of the evaluation is all relevant factors considered. The evaluation set of each factor is determined in accordance with the evaluation results of experts. The membership degree vector can be obtained by combining the weight set. Finally, the fuzzy comprehensive evaluation result can be obtained according to the evaluation standard [31].

2.2. Operation Process of Fuzzy Analytic Hierarchy Process. For specific operations of the fuzzy analytic hierarchy process, different items have diverse operations. The risk assessment of the stability of deep three-soft coal seam outburst roof can be implemented in four stages [32], including model design, expert consultation, matrix establishment, calculation analysis, and analysis report formation, as shown in Figure 1.

\subsection{Decision-Making Steps of Fuzzy Analytic Hierarchy Process}

Step 1. Create a hierarchical structure diagram.

Establish an analytic hierarchy process diagram to identify the risks of the project.

Step 2. Calculate the weights of primary and secondary indicators.

Compare each factor in the criterion layer with each factor (scheme) in the scheme layer and score the importance with the number within the interval $[1,9]$ to form a judgment matrix. After being tested by the consistency ratio $C \times R=\lambda_{\max }-n /(n-1) R \times I<0.1, \quad$ the weights $w_{i}^{\prime}=\left(w_{1}, w_{2}, \ldots, w_{i}\right)$ are normalized to get $w_{i}$, which satisfies $0 \leq w_{i} \leq 1$, and $\sum_{i=1}^{k} w_{i}=1$.

The values of $R I$ in the consistency check list can be found in Table 1.

A matrix $W$ with $k$ rows and $n$ columns can be obtained by combing several weight vectors:

$$
W=\left[\begin{array}{cccc}
W_{11} & W_{12} & \ldots & W_{1 n} \\
W_{21} & W_{21} & \ldots & W_{2 n} \\
\vdots & \ddots & \ddots & \vdots \\
W_{k 1} & W_{k 2} & \ldots & W_{k n}
\end{array}\right] .
$$




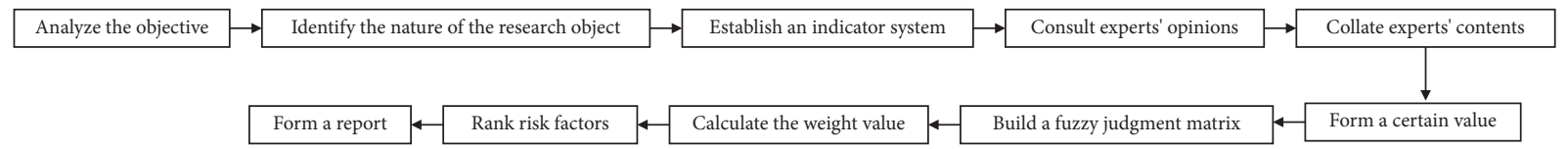

FIGURE 1: Specific operation process.

TABLE 1: Values of randomness indicators.

\begin{tabular}{lcccccccccc}
\hline $\begin{array}{l}\text { Matrix } \\
\text { order }\end{array}$ & 3 & 4 & 5 & 6 & 7 & 8 & 9 & 10 & 11 & 12 \\
\hline$R \cdot I$ & 0.52 & 0.89 & 1.12 & 1.26 & 1.36 & 1.41 & 1.46 & 1.49 & 1.52 & 1.54 \\
\hline
\end{tabular}

Step 3. Determine the fuzzy vector and comment set.

Each factor in the indicator layer was scored by 10 experts. The score vector $R_{i}=\left(R_{i 1}, R_{i 2}, \ldots, R_{i n} i=1,2\right.$, $\ldots, k$ ) of the $i$-th factor $C_{i}$ can be obtained, and the comment set $V=\left\{v_{1}, v_{2}, v_{3}, v_{4}, v_{5}\right\}$ [33] is also determined.

Step 4. Perform the comprehensive risk assessment.

The weight of each risk factor is $W=\left\{W_{1}, W_{2}\right.$, $\left.W_{3}, \ldots W_{n}\right\}$, and the evaluation matrix is $B_{i j}$, where $W_{1}+W_{2}+\cdots+W_{m}=1, B_{i j}=W_{i} \times R_{i j}$.

Then, the comprehensive evaluation grade score of $A$ is

$$
f=\sum_{j=1}^{n} v_{i} \times B_{i j}, \quad(i, j=1,2, \ldots, n) .
$$

After the grade score corresponding to each factor of the criterion layer is calculated, the corresponding risk level can be obtained in accordance with the score interval in the comment set $V=\left\{v_{1}, v_{2}, v_{3}, v_{4}, v_{5}\right\}$.

\section{Project Case}

\subsection{Basic Overview of Lugou Mine}

(1) General Situation of Working Face. No. 32141 working face is located in the lower part of the west wing of No. 32 mining area, as the replacement face of the upper working face of No. 21 coal pillars. The working face is located to the west of No. 32 haulage downhill, the mined-out area of No. 32121 working face is located in the north, and the coal pillar protected by Weizhai fault and its branch fault is located in the south. The underground elevation of this surface is $-325 \sim-261 \mathrm{~m}$, and the ground elevation is $+215 \sim+240 \mathrm{~m}$. The southeast of the working surface is Wuxing Reservoir, the west is Wangjiamen, the south is Magou village housing and primary school, and the north is Wuxing Reservoir and orchard. The working face is arranged along the direction of the coal seam, with an average inclined length of $120 \mathrm{~m}$ and an average mining strike length of $720 \mathrm{~m}$. It has an area of $84279 \mathrm{~m}^{2}$. The coal seam thickness ranges from $1.0 \mathrm{~m}$ to $22.0 \mathrm{~m}$ with an average of $8.0 \mathrm{~m}$. The recoverable reserve is 750,000 tons. It uses the one-time full-thickness mining technology of fully mechanized caving coal.
(2) Coal Seam Situation. The average coal seam thickness in the mining area of No. 32141 working face is about $8.0 \mathrm{~m}$, and the coal seam inclination angle is $7^{\circ}-20^{\circ}$, with an average of $13^{\circ}$. The coal seam has a simple structure, presenting to be black powder scaly. The lump coal is hard with a metallic luster. Influenced by the oblique structure, the roof and floor of the coal seam have local undulating changes, belonging to unstable coal seams; the immediate roof is mud stone with a thickness ranging from $1 \mathrm{~m}$ to $2.5 \mathrm{~m}$ and an average thickness of $2.0 \mathrm{~m}$. There are argillaceous bands, dark gray, rich in plant fossils, and a large number of mica.

(3) Coal Seam Roof Situation. The upper roof is medium-grained sandstone and fine-grained sandstone, with a thickness ranging from $18.5 \mathrm{~m}$ to $22.0 \mathrm{~m}$ and an average thickness of $20.0 \mathrm{~m}$. They are gray or dark gray, thick layered with a medium-grained structure. They are mainly composed of quartz, containing mica flakes and pyrite nodules; there is no false roof on this surface; the immediate bottom is mudstone and sandy mudstone, with thickness ranging from $14.0 \mathrm{~m}$ to $20.0 \mathrm{~m}$ and an average thickness of $15.0 \mathrm{~m}$. They are dark gray mudstone containing plant fossils. They are mainly composed of quartz, followed by feldspar, containing mica flakes and pyrite scattered crystals. There are friction mirrors and scratches; the lower floor is L7-8 limestone, and the thickness ranges from $12.0 \mathrm{~m}$ to $13.0 \mathrm{~m}$ with an average of $12.5 \mathrm{~m}$. It is black-gray, dense, and hard, with well-developed karst fissures and good water richness. There are a large number of calcite veins and pyrite crystals.

(4) Geological Structure. According to the analysis of actual exposure data of nearby tunnels, No. 32141 working face has an axially syncline structure near the north-south direction as a whole. The coal seam is unstable. The coal thickness ranges from $1.0 \mathrm{~m}$ to $22.0 \mathrm{~m}$. The average coal thickness is about $8 \mathrm{~m}$. There is a thick coal area near the oblique axis of the working face (the thickness of the coal seam ranges from $10 \mathrm{~m}$ to $22 \mathrm{~m}$ ). It is expected that the crustal stress is concentrated in the area towards the oblique axis, and the coal seam stratum is extremely broken. According to the 3D seismic and geophysical data, as well as the actual exposure data of nearby tunnels, there are six faults in the working face: (1) DF5 $187^{\circ}<65 \sim 75^{\circ} \quad H=0 \sim 6.0 \mathrm{~m} ; \quad$ (2) $\quad \mathrm{F} 32-8 \quad 176^{\circ}<45^{\circ}$ $H=0 \sim 9.0 \mathrm{~m}$; (3) F32 $-16204^{\circ}<60^{\circ} H=0 \sim 7.0 \mathrm{~m}$; (4) F32-4 $192^{\circ}<65 \sim 78^{\circ} \quad H=0 \sim 7.0 \mathrm{~m}$; (5) $\quad \mathrm{F} 32-29$ $310^{\circ}<65 \sim 72^{\circ} \quad H=0 \sim 4.0 \mathrm{~m}$; (6) F32- $14325^{\circ}<72^{\circ}$ $H=0 \sim 1.0 \mathrm{~m}$. There is the Weizhai fault and its 
branch faults in the southern part of No. 32141 working face. The fault drop is relatively large. Based on the geological structure analysis above, the geological structure of this area is relatively complex. It is expected that there may be hidden structures in the working face. It is necessary to strengthen the detection of the geological structure during the excavation.

\subsection{Risks and Harmful Factors}

(1) Risks of Geological Environment. The coal seam in No. 32141 working face of Lugou Coal Mine has a simple structure, which is black scaly powder. The lump coal is hard with a metallic luster. Influenced by the oblique structure, the roof and floor of the coal seam have local undulating changes, belonging to unstable coal seams; the geological environment is complex, so there are inherent risks such as coal and rock gas content, geological structure, deep stress concentration, coal outburst characteristics, and gas emission.

(2) Risks of Safety Management. Since the Lugou Mine project is large and involves many people, making its management difficult, safety education, safety rules and regulations, and emergency drilling have become the main contents of management.

(3) Risks of Safety Facilities. Due to the existence of gas, $\mathrm{CO}$, and other gases, in order to prevent personnel poisoning and gas explosion hazards during the excavation process, the ventilation requirements of the coal mine must be quite high; the ventilation issue has become the primary risk for three-soft coal seams. In addition, monitoring systems, fire-fighting systems, transportation systems, and protective rescue facilities are also risk sources.

(4) Risks of Construction Personnel. For construction personnel, the risks mainly come from the unreasonable arrangement of personnel, weak safety awareness, and weak ideological and political qualities.

3.3. Establishment of a Risk Assessment Indicator System. From the identification of main risk factors in Section 3.2, it can be found that there are 23 levels of main risks and harmful factors affecting the project, which can be divided into three layers: target layer, primary indicator layer, and secondary indicator layer. The corresponding factor set is $A=C 1, C 2, \ldots, C 23$, as shown in Figure 2 .

\subsection{Weight Calculation of Indicators}

3.4.1. Weight Calculation of Primary Indicators. From the risk assessment indicator system diagram of the three-soft coal seam outburst roof stability of the Lugou Mine, it can be known that there are 4 primary indicator factors. After the weights of these 5 indicators are calculated by the analytic hierarchy process, the judgment matrix $A=\left(v_{i j}\right)_{n \times n}$ can be constructed, as shown in Table 2.

The square root method is used to solve the approximate value $w_{i}^{\prime}$ of the weight vector of the evaluation factor:

$$
\begin{aligned}
& w_{i}^{\prime}=\left(\prod_{j=1}^{n} a_{i j}\right)^{1 / n}, \quad(i=1,2, \cdots, n) \\
& w_{1}^{\prime}=\left(1 \times 1 \times \frac{1}{3} \times \frac{1}{2} \times \frac{1}{2}\right)^{1 / 5}=0.6084 \\
& w_{2}^{\prime}=\left(1 \times 1 \times \frac{1}{3} \times \frac{1}{3} \times 1\right)^{1 / 5}=0.6444 \\
& w_{3}^{\prime}=\left(3 \times 3 \times 1 \times \frac{1}{2} \times 1\right)^{1 / 5}=1.3510 \\
& w_{4}^{\prime}=\left(2 \times 3 \times 2 \times 1 \times \frac{1}{2}\right)^{1 / 5}=1.4310 \\
& w_{5}^{\prime}=(2 \times 1 \times 1 \times 2 \times 1)^{1 / 5}=1.3195
\end{aligned}
$$

After the normalization of $w_{i}^{\prime}$, the evaluation factor weight vector $w_{i}$ can be obtained. The relationship is

$$
w_{i}=\frac{w_{i}^{\prime}}{\sum_{k=1}^{n}\left(\prod_{j=1}^{n} a_{k j}\right)}, \quad(1,2, \ldots, n)
$$

Get

$$
\begin{aligned}
& w_{1}=0.1136 \text {, } \\
& w_{2}=0.1204 \text {, } \\
& w_{3}=0.2523 \text {, } \\
& w_{4}=0.2673 \text {, } \\
& w_{5}=0,2464 \text {, } \\
& A=\left(\begin{array}{lllll}
0.1136 & 0.1204 & 0.2523 & 0.2673 & 0.2464
\end{array}\right) .
\end{aligned}
$$

Python is used to obtain the value of $\lambda$ and find $\lambda_{\max }=5.3930$. From Table 1 , it can be obtained that $R \cdot I=1.12$. After being substituted into the formula, the following can be obtained:

$$
C \times R=\frac{\lambda_{\max }-n}{(n-1) R \times I}=\frac{4.0206-4}{(4-1) \times 0.89}=0.0078<0.1 .
$$

It shows that the discriminant matrix satisfies the consistency requirement, that is, the obtained eigenvector is valid.

3.4.2. Weight Calculation of Secondary Indicators. The analytic hierarchy process is still used to calculate the weight of indicators.

(1) First, establish the judgment matrix for $B_{1}$ geological environment risk.

Similarly, the following can be obtained from the data calculation in Table 3: 


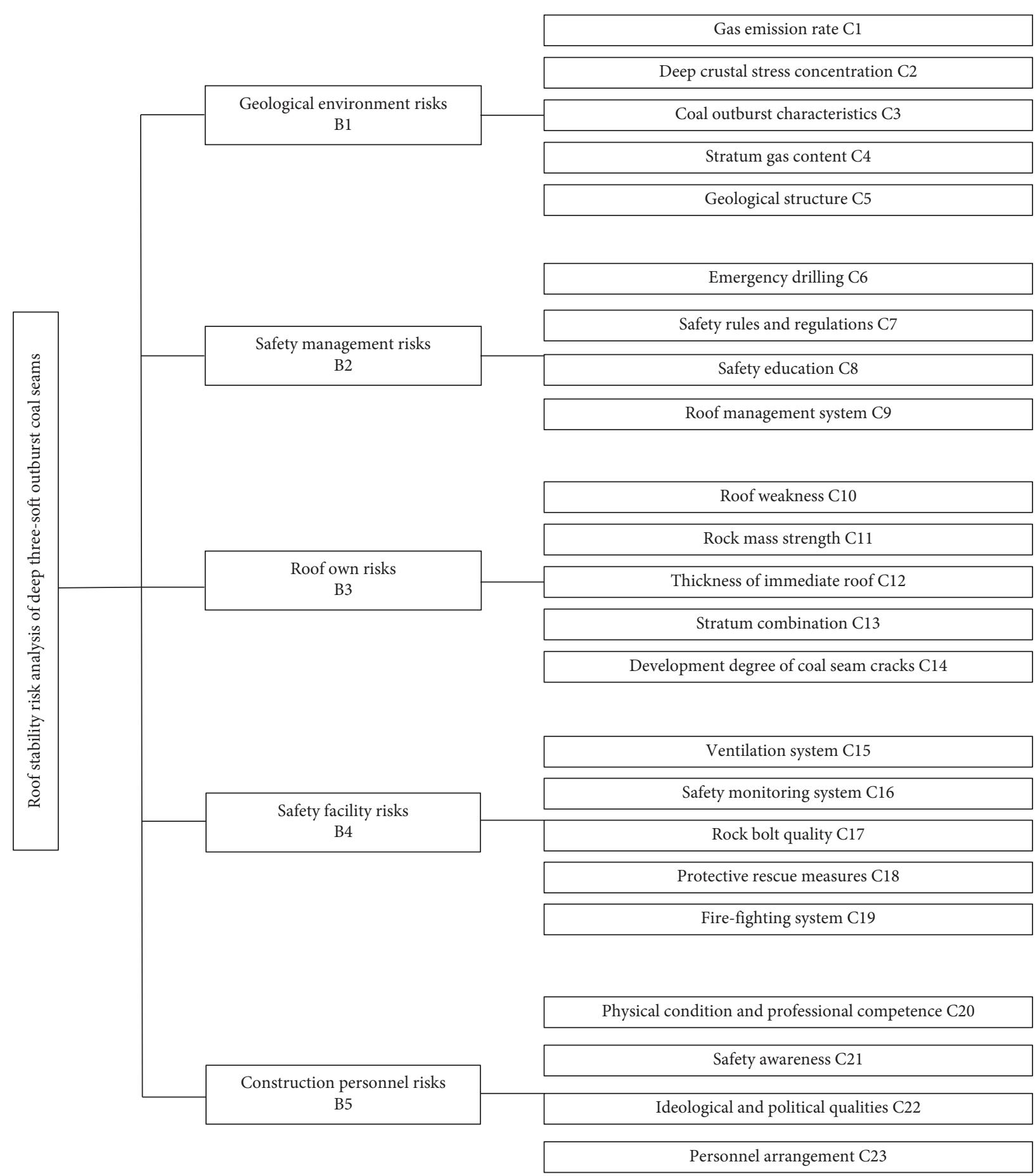

FIGURE 2: Stability risk assessment indicators of Lugou Mine's three-soft coal seam outburst roof.

TABLE 2: $B-B$ judgment matrix.

\begin{tabular}{lccccc}
\hline Target layer A & $B 1$ & $B 2$ & $B 3$ & $B 4$ & $B 5$ \\
\hline$B 1$ & 1 & 1 & $1 / 3$ & $1 / 2$ & $1 / 2$ \\
$B 2$ & 1 & 1 & $1 / 3$ & $1 / 3$ & 1 \\
$B 3$ & 3 & 3 & 1 & $1 / 2$ & 1 \\
$B 4$ & 2 & 3 & 2 & 1 & $1 / 2$ \\
$B 5$ & 2 & 1 & 1 & 2 & 1 \\
\hline
\end{tabular}

$\lambda_{\max }=5.0264$,

$W_{B 1}=\left(\begin{array}{lllll}0.3243 & 0.1495 & 0.3243 & 0.1271 & 0.0748\end{array}\right)$.

From Table 1, it can be obtained that $R \cdot I=1.12$. After being substituted into formula (6), it can be obtained that $C \times R=0.0059<0.1$. 
TABLE 3: $B 1-C$ judgment matrix.

\begin{tabular}{cccccccc}
\hline$B 1$ & $C 1$ & $C 2$ & $C 3$ & $C 4$ & $C 5$ & $W_{i}^{\prime}$ & $W I$ \\
\hline$C 1$ & 1 & 2 & 1 & 3 & 4 & 1.8882 & 0.3243 \\
$C 2$ & $1 / 2$ & 1 & $1 / 2$ & 1 & 2 & 0.8706 & 0.1495 \\
$C 3$ & 1 & 2 & 1 & 3 & 4 & 1.8882 & 0.3243 \\
$C 4$ & $1 / 3$ & 1 & $1 / 3$ & 1 & 2 & 0.7402 & 0.1271 \\
$C 5$ & $1 / 4$ & $1 / 2$ & $1 / 4$ & $1 / 2$ & 1 & 0.4353 & 0.0748 \\
\hline
\end{tabular}

It shows that the discriminant matrix satisfies the consistency requirement, that is, the obtained eigenvector is valid.

(2) Establish a judgment matrix for B2 safety management.

The following can be obtained from the data calculation in Table 4:

$$
\begin{aligned}
& \lambda_{\max }=4.0206, \\
& W_{B 1}=\left(\begin{array}{llll}
0.5032 & 0.0839 & 0.1856 & 0.2273
\end{array}\right) .
\end{aligned}
$$

From Table 1, it can be obtained that $R * I=0.89$. After being substituted into formula (6), it can be obtained that $C \times R=0.0077<0.1$.

It shows that the discriminant matrix satisfies the consistency requirement, that is, the obtained eigenvector is valid.

(3) Establish a judgment matrix for B3 roof factors.

The following can be obtained from the data calculation in Table 5:

$\lambda_{\max }=5.4473$,

$W_{B 1}=\left(\begin{array}{lllll}0.3332 & 0.1723 & 0.2027 & 0.1870 & 0.1048\end{array}\right)$.

From Table 1, it can be obtained that $R \times I=1.12$. After being substituted into formula (6), it can be obtained that $C \times R=0.0998<0.1$.

It shows that the discriminant matrix satisfies the consistency requirement, that is, the obtained eigenvector is valid.

(4) Establish a judgment matrix for B4 safety facilities.

The following can be obtained from the data calculation in Table 6:

$\lambda_{\text {max }}=5.0133$,

$W_{B 1}=\left(\begin{array}{lllll}0.1094 & 0.3682 & 0.2065 & 0.1094 & 0.2065\end{array}\right)$.
TABLE 4: B2-C judgment matrix.

\begin{tabular}{ccccccc}
\hline B2 & C6 & C7 & $C 8$ & $C 9$ & $W_{i}^{\prime}$ & $W I$ \\
\hline C6 & 1 & 6 & 3 & 2 & 2.4495 & 0.5032 \\
C7 & $1 / 6$ & 1 & $1 / 2$ & $1 / 3$ & 0.4082 & 0.0839 \\
C8 & $1 / 3$ & 2 & 1 & 1 & 0.9036 & 0.1856 \\
C9 & $1 / 2$ & 3 & 1 & 1 & 1.1067 & 0.2273 \\
\hline
\end{tabular}

TABle 5: $B 3-C$ judgment matrix.

\begin{tabular}{lccccccc}
\hline B3 & $C 10$ & $C 11$ & $C 12$ & $C 13$ & $C 14$ & $W_{i}^{\prime}$ & $W I$ \\
\hline$C 10$ & 1 & 3 & 1 & 2 & 3 & 1.7826 & 0.3332 \\
$C 11$ & $1 / 3$ & 1 & 1 & 2 & 1 & 0.9221 & 0.1723 \\
$C 12$ & 1 & 1 & 1 & $1 / 2$ & 3 & 1.0845 & 0.2027 \\
$C 13$ & $1 / 2$ & $1 / 2$ & 2 & 1 & 2 & 1.0000 & 0.1870 \\
$C 14$ & $1 / 3$ & 1 & $1 / 3$ & $1 / 2$ & 1 & 0.5610 & 0.1048 \\
\hline
\end{tabular}

TABLe 6: B4- $C$ judgment matrix.

\begin{tabular}{lccccccc}
\hline$B_{4}$ & $C 15$ & $C 16$ & $C 17$ & $C 18$ & $C 19$ & $W_{i}^{\prime}$ & $W I$ \\
\hline$C 15$ & 1 & $1 / 3$ & $1 / 2$ & 1 & $1 / 2$ & 0.6084 & 0.1094 \\
$C 16$ & 3 & 1 & 2 & 3 & 2 & 2.0477 & 0.3682 \\
$C 17$ & 2 & $1 / 2$ & 1 & 2 & 1 & 1.1487 & 0.2065 \\
$C 18$ & 1 & $1 / 3$ & $1 / 2$ & 1 & $1 / 2$ & 0.6084 & 0.1094 \\
$C 19$ & 2 & $1 / 2$ & 1 & 2 & 1 & 1.1487 & 0.2065 \\
\hline
\end{tabular}

From Table 1 , it can be obtained that $R \times I=1.12$. After being substituted into formula (6), it can be obtained that $C \times R=0.0030<0.1$.

It shows that the discriminant matrix satisfies the consistency requirement, that is, the obtained eigenvector is valid.

(5) Establish a judgment matrix for B5 construction personnel.

The following can be obtained from the data calculation in Table 7:

$$
\begin{aligned}
& \lambda_{\max }=4, \\
& W_{B 1}=\left(\begin{array}{llll}
0.1250 & 0.5000 & 0.2500 & 0.1250
\end{array}\right) .
\end{aligned}
$$

From Table 1, it can be obtained that $R \times I=0.89$. After being substituted into formula (6), it can be obtained that $C \times R=0<0.1$.

It shows that the discriminant matrix satisfies the consistency requirement, that is, the obtained eigenvector is valid. 
TABLe 7: B5-C judgment matrix.

\begin{tabular}{ccccccc}
\hline B5 & $C 20$ & $C 21$ & $C 22$ & $C 23$ & $W_{i}^{\prime}$ & $W I$ \\
\hline$C 20$ & 1 & $1 / 4$ & $1 / 2$ & 1 & 0.5946 & 0.1250 \\
$C 21$ & 4 & 1 & 2 & 4 & 2.3784 & 0.5000 \\
$C 22$ & 2 & $1 / 2$ & 1 & 2 & 1.1892 & 0.2500 \\
$C 23$ & 1 & $1 / 4$ & $1 / 2$ & 1 & 0.5946 & 0.1250 \\
\hline
\end{tabular}

3.4.3. Ranking of Risk Factors. From the calculation above, it can be known that the weight of each factor on the safety of gas tunnel construction is

$$
\begin{aligned}
& A=\left(\begin{array}{lllll}
0.1136 & 0.1204 & 0.2523 & 0.2673 & 0.2464
\end{array}\right), \\
& W_{1}=0.1136 \times\left(\begin{array}{lllll}
0.3243 & 0.1495 & 0.3243 & 0.1271 & 0.0748
\end{array}\right) \\
& =\left(\begin{array}{lllll}
0.0368 & 0.0167 & 0.0368 & 0.0144 & 0.0085
\end{array}\right), \\
& W_{2}=0.1204 \times\left(\begin{array}{llll}
0.5031 & 0.0839 & 0.1856 & 0.2273
\end{array}\right)
\end{aligned}
$$

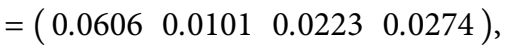

$$
\begin{aligned}
& W_{3}=0.2523 \times\left(\begin{array}{lllll}
0.3332 & 0.1723 & 0.2027 & 0.1870 & 0.1048
\end{array}\right) \\
& =\left(\begin{array}{lllll}
0.0841 & 0.04435 & 0.0511 & 0.472 & 0.0264
\end{array}\right), \\
& W_{4}=0.2673 \times\left(\begin{array}{lllll}
0.1094 & 0.3682 & 0.2065 & 0.1094 & 0.2065
\end{array}\right)
\end{aligned}
$$

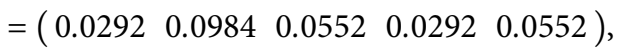

$$
\begin{aligned}
& W_{5}=0.2464 \times\left(\begin{array}{llll}
0.1250 & 0.5000 & 0.2500 & 0.1250
\end{array}\right) \\
& =\left(\begin{array}{llll}
0.0308 & 0.1231 & 0.0616 & 0.0308
\end{array}\right) .
\end{aligned}
$$

According to the total weight of the $C$ layer calculated above, all risk factors are ranked based on the weight value, as shown in Table 8.

The ranking above shows the evaluation results of risk factors of Lugou Mine's three-soft coal seam outburst roof stability. During the evaluation process, 10 experts were invited to score various risk factors in the Anping Gas Tunnel Construction Safety Project. Statistical methods were used to calculate the final weight value of different factors. Based on the weight value, it can be concluded that safety awareness, safety monitoring system, roof weakness, ideological and political qualities, fire-fighting system, and rock bolt quality dominate the whole project; among them, the riskiest factors are safety awareness and safety monitoring system. In other words, if gas emission cannot be effectively controlled and detected, the safety awareness of workers cannot be improved, and coal mines will have accidents such as poisoning and gas outbursts, which may eventually cause coal mines to stop production. Moreover, roof weakness is also a risk factor, which means that if the tunnel support measures are not done well, roof fall accidents may occur.

3.5. Establishment of Safety Rating. After on-site survey by experts, the Anping Gas Tunnel single-factor score comment set is $V=\left\{v_{1}, v_{2}, v_{3}, v_{4}, v_{5}\right\}$, corresponding to five grades, namely, "very good," "good," "average," "poor," and "very bad." The evaluation set is represented by $(95,85,65,45,30)$, as shown in Table 9. Relationship between scores and safety grades is shown in Table 10.

Generally, basic methods such as expert survey method, CIM method, and Monte Carlo simulation method are used for risk assessment [34]. In order to simplify the calculation and obtain the corresponding data, this chapter used the expert survey method.

The expert evaluation method was adopted. 10 experts were invited to make judgments on possible risks and their grades, and then they scored according to indicators. The statistics based on the judgment values given by the experts are shown in Table 11.

(1) Establish the fuzzy evaluation matrix $R_{i}$. Obtain the fuzzy evaluation matrix $R_{i}$ after being scored by experts.

$$
\begin{aligned}
& R_{1}=\left[\begin{array}{ccccc}
0 & 0.2 & 0.3 & 0.4 & 0.1 \\
0.1 & 0.4 & 0.2 & 0.1 & 0.2 \\
0.1 & 0.2 & 0.2 & 0.3 & 0.2 \\
0 & 0.3 & 0.2 & 0.3 & 0.2 \\
0.2 & 0.4 & 0.2 & 0.2 & 0
\end{array}\right], \\
& R_{2}=\left[\begin{array}{ccccc}
0.4 & 0.3 & 0.2 & 0.1 & 0 \\
0.2 & 0.2 & 0.2 & 0.2 & 0.2 \\
0 & 0.3 & 0.2 & 0.4 & 0.1 \\
0.1 & 0.3 & 0.4 & 0.2 & 0
\end{array}\right], \\
& R_{3}=\left[\begin{array}{ccccc}
0 & 0.2 & 0.3 & 0.3 & 0.2 \\
0.3 & 0.5 & 0.1 & 0.1 & 0 \\
0.1 & 0.3 & 0.4 & 0.1 & 0.1 \\
0.3 & 0.4 & 0.2 & 0.1 & 0 \\
0.2 & 0.4 & 0.3 & 0.1 & 0
\end{array}\right] \text {, } \\
& R_{4}=\left[\begin{array}{ccccc}
0.6 & 0.2 & 0.2 & 0 & 0 \\
0.4 & 0.2 & 0.2 & 0 & 0.2 \\
0.2 & 0.3 & 0.3 & 0.2 & 0 \\
0.2 & 0.4 & 0.2 & 0.2 & 0 \\
0.4 & 0.2 & 0.3 & 0.1 & 0
\end{array}\right] \text {, } \\
& R_{5}=\left[\begin{array}{ccccc}
0.2 & 0.2 & 0.2 & 0.2 & 0.2 \\
0 & 0.3 & 0.2 & 0.4 & 0.1 \\
0.1 & 0.3 & 0.3 & 0.3 & 0 \\
0.3 & 0.2 & 0.2 & 0.3 & 0
\end{array}\right] \text {. }
\end{aligned}
$$

(2) Solve the evaluation matrix $B_{i}$ of each factor. According to the formula,

$$
B_{i}=W_{B i} \times R_{i} .
$$

The evaluation matrix of each factor is as follows: 
TABLE 8: Total ranking of risk factors.

\begin{tabular}{lr}
\hline Specific risk factor & Total weight \\
\hline Safety awareness & 0.1232 \\
Safety monitoring system & 0.0984 \\
Roof weakness & 0.0841 \\
Ideological and political qualities & 0.0616 \\
Ventilation system & 0.0606 \\
Fire-fighting system & 0.0553 \\
Rock bolt quality & 0.0552 \\
Thickness of immediate roof & 0.0511 \\
Stratum combination & 0.0472 \\
Rock mass strength & 0.0435 \\
Gas emission & 0.0368 \\
Coal outburst characteristics & 0.0368 \\
Physical condition and professional competence & 0.0308 \\
Personnel arrangement & 0.0308 \\
Emergency drilling & 0.0292 \\
Tunnel support factor & 0.0292 \\
Roof management system & 0.0274 \\
Development degree of coal seam cracks & 0.0264 \\
Safety education & 0.0223 \\
Deep crustal stress concentration & 0.0167 \\
Stratum gas content & 0.0144 \\
Safety rules and regulations & 0.0101 \\
Geological structure & 0.0085 \\
\hline
\end{tabular}

Table 9: Relationship between scores and safety grades.

\begin{tabular}{lccccc}
\hline Grade & Very good & Good & Average & Poor & Very bad \\
\hline Score & 95 & 85 & 65 & 45 & 30 \\
\hline
\end{tabular}

TABLE 10: Relationship between scores and safety grades.

\begin{tabular}{lccccc}
\hline Grade & Grade I & Grade II & Grade III & Grade IV & Grade V \\
\hline Description & Little influence & Small influence & General influence & Large influence & Significant influence \\
Score range & $>90$ & $80-90$ & $60-79$ & $40-59$ & $<40$ \\
\hline
\end{tabular}

TABLE 11: Scoring statistics of weights and expert safety grades.

\begin{tabular}{|c|c|c|c|c|c|c|c|c|}
\hline $\begin{array}{l}\text { Primary evaluation } \\
\text { factors }\end{array}$ & $\begin{array}{l}\text { Weight of primary } \\
\text { evaluation factors }\end{array}$ & $\begin{array}{c}\text { Secondary } \\
\text { evaluation factors }\end{array}$ & $\begin{array}{l}\text { Weight of secondary } \\
\text { evaluation factors }\end{array}$ & $\begin{array}{l}\text { Very } \\
\text { good }\end{array}$ & Good & Average & Poor & $\begin{array}{l}\text { Very } \\
\text { bad }\end{array}$ \\
\hline \multirow{5}{*}{$\begin{array}{l}\text { Geological } \\
\text { environment risks }\end{array}$} & \multirow{5}{*}{0.1136} & $C 1$ & 0.3243 & 0 & 0.2 & 0.3 & 0.4 & 0.1 \\
\hline & & $C 2$ & 0.1495 & 0.1 & 0.4 & 0.2 & 0.1 & 0.2 \\
\hline & & C3 & 0.3243 & 0.1 & 0.2 & 0.2 & 0.3 & 0.2 \\
\hline & & $C 4$ & 0.1271 & 0 & 0.3 & 0.2 & 0.3 & 0.2 \\
\hline & & C5 & 0.0748 & 0.2 & 0.4 & 0.2 & 0.2 & 0 \\
\hline \multirow{4}{*}{$\begin{array}{l}\text { Safety management } \\
\text { risks }\end{array}$} & \multirow{4}{*}{0.1204} & C6 & 0.5032 & 0.4 & 0.3 & 0.2 & 0.1 & 0 \\
\hline & & $C 7$ & 0.0893 & 0.2 & 0.2 & 0.2 & 0.2 & 0.2 \\
\hline & & $C 8$ & 0.1856 & 0 & 0.3 & 0.2 & 0.4 & 0.1 \\
\hline & & C9 & 0.2273 & 0.1 & 0.3 & 0.4 & 0.2 & 0 \\
\hline \multirow{5}{*}{ Roof own risks } & \multirow{5}{*}{0.2523} & $C 10$ & 0.3332 & 0 & 0.2 & 0.3 & 0.3 & 0.2 \\
\hline & & $C 11$ & 0.1723 & 0.3 & 0.5 & 0.1 & 0.1 & 0 \\
\hline & & $C 12$ & 0.2027 & 0.1 & 0.3 & 0.4 & 0.1 & 0.1 \\
\hline & & $C 13$ & 0.1870 & 0.3 & 0.4 & 0.2 & 0.1 & 0 \\
\hline & & $C 14$ & 0.1048 & 0.2 & 0.4 & 0.3 & 0.1 & 0 \\
\hline
\end{tabular}


Table 11: Continued.

\begin{tabular}{|c|c|c|c|c|c|c|c|c|}
\hline $\begin{array}{l}\text { Primary evaluation } \\
\text { factors }\end{array}$ & $\begin{array}{l}\text { Weight of primary } \\
\text { evaluation factors }\end{array}$ & $\begin{array}{c}\text { Secondary } \\
\text { evaluation factors }\end{array}$ & $\begin{array}{l}\text { Weight of secondary } \\
\text { evaluation factors }\end{array}$ & $\begin{array}{l}\text { Very } \\
\text { good }\end{array}$ & Good & Average & Poor & $\begin{array}{l}\text { Very } \\
\text { bad }\end{array}$ \\
\hline \multirow{5}{*}{ Safety facility risks } & \multirow{5}{*}{0.2673} & $C 15$ & 0.1094 & 0.6 & 0.2 & 0.2 & 0 & 0 \\
\hline & & $C 16$ & 0.3682 & 0.4 & 0.2 & 0.2 & 0 & 0.2 \\
\hline & & $C 17$ & 0.2065 & 0.2 & 0.3 & 0.3 & 0.2 & 0 \\
\hline & & $C 18$ & 0.1094 & 0.2 & 0.4 & 0.2 & 0.2 & 0 \\
\hline & & $C 19$ & 0.2065 & 0.4 & 0.2 & 0.3 & 0.1 & 0 \\
\hline \multirow{4}{*}{$\begin{array}{l}\text { Construction } \\
\text { personnel risks }\end{array}$} & \multirow{4}{*}{0.2464} & $C 20$ & 0.1250 & 0.2 & 0.2 & 0.2 & 0.2 & 0.2 \\
\hline & & $C 21$ & 0.5000 & 0 & 0.3 & 0.2 & 0.4 & 0.1 \\
\hline & & $C 22$ & 0.2500 & 0.1 & 0.3 & 0.3 & 0.3 & 0 \\
\hline & & $C 23$ & 0.1250 & 0.3 & 0.2 & 0.2 & 0.3 & 0 \\
\hline
\end{tabular}

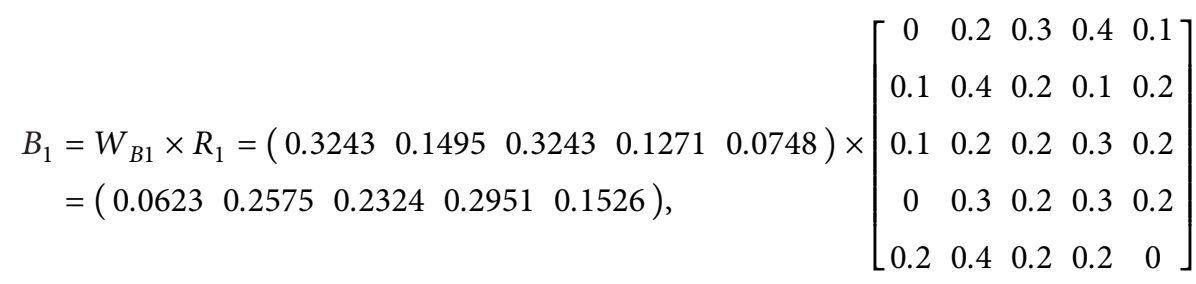

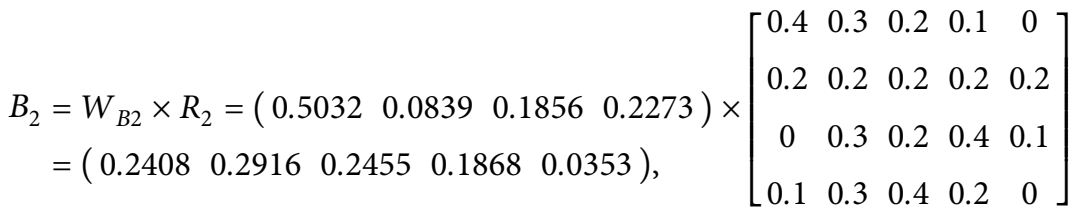

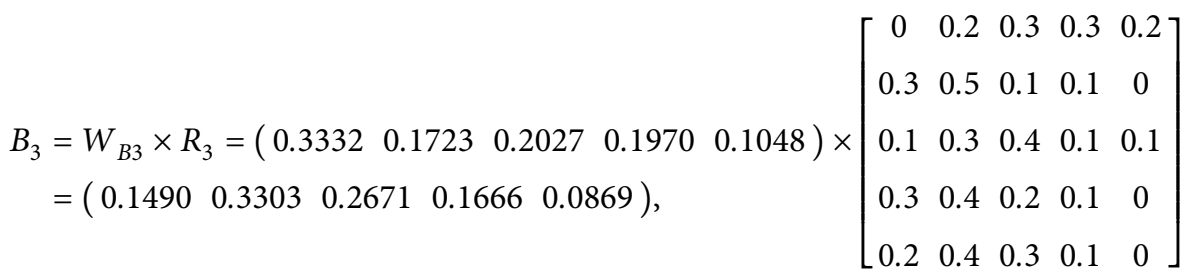

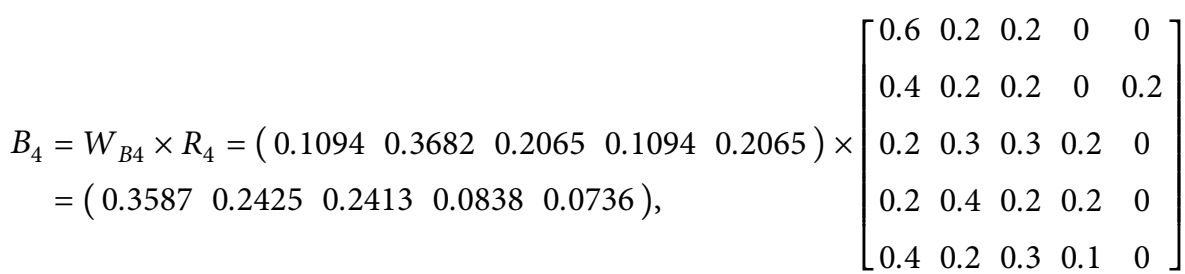

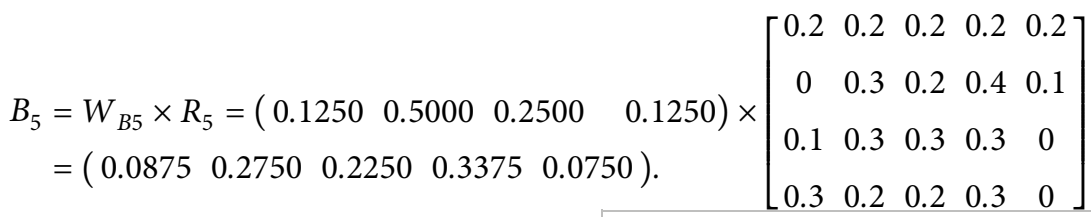

(3) Obtain the total evaluation matrix $R$ : 


$$
R=\left[\begin{array}{ccccc}
0.0623 & 0.2575 & 0.2324 & 0.2951 & 0.1562 \\
0.2408 & 0.2916 & 0.2455 & 0.1868 & 0.0353 \\
0.1490 & 0.3303 & 0.2671 & 0.1666 & 0.0869 \\
0.3587 & 0.2425 & 0.2413 & 0.838 & 0.0736 \\
0.0857 & 0.2750 & 0.2250 & 0.3375 & 0.0750
\end{array}\right]
$$

(4) Comprehensive factor evaluation matrix: the following can be obtained from the formula $B=A \times R$ :

$$
\begin{aligned}
B= & A \times R=\left(\begin{array}{lllll}
0.1136 & 0.1209 & 0.2523 & 0.2673 & 0.2464
\end{array}\right) \\
& \times\left[\begin{array}{lllll}
0.0623 & 0.2575 & 0.2324 & 0.2951 & 0.1562 \\
0.2408 & 0.2916 & 0.2455 & 0.1868 & 0.0353 \\
0.1490 & 0.3303 & 0.2671 & 0.1666 & 0.0869 \\
0.3587 & 0.2425 & 0.2413 & 0.838 & 0.0736 \\
0.0857 & 0.2750 & 0.2250 & 0.3375 & 0.0750
\end{array}\right] \\
= & \left(\begin{array}{lllll}
0.19 & 0.28 & 0.24 & 0.20 & 0.08
\end{array}\right) .
\end{aligned}
$$

(5) Grading:

$$
\begin{aligned}
f_{i}= & \sum_{i=1}^{n} v_{i} \times B_{i j}, \quad(i, j=1,2, \ldots, n), \\
f_{1}= & 95 \times 0.0623+85 \times 0.2575+65 \times 0.2324 \\
& +45 \times 0.2951+30 \times 0.1526=60, \\
f_{2}= & 95 \times 0.2408+85 \times 0.2916+65 \times 0.2455 \\
& +45 \times 0.1868+30 \times 0.0353=73, \\
f_{3}= & 95 \times 0.1490+85 \times 0.3303+65 \times 0.2671 \\
& +45 \times 0.1666+30 \times 0.0869=70, \\
f_{4}= & 95 \times 0.3587+85 \times 0.2425+65 \times 0.2413 \\
& +45 \times 0.0838+30 \times 0.0736=76, \\
f_{5}= & 95 \times 0.0875+85 \times 0.2750+65 \times 0.2250 \\
& +45 \times 0.3375+30 \times 0.0750=64 .
\end{aligned}
$$

From the above calculations, it can be known from Table 10 that the safety grades of these four types of factors are as follows: the safety grade of the geological environment is "average," the safety grade of the safety management is "average," the safety grade of the roof itself is "average," the safety grade of the safety facilities is "average," and the safety grade of the construction personnel is "average." The total score of the system is $f=95 \times 0.19+85 \times 0.28+65 \times$ $0.24+45 \times 0.20+30 \times 0.08=69$, and the safety grade of Lugou Mine's three-soft coal seam outburst roof stability is "average."

(6) Evaluation results: from the fuzzy analytic hierarchy process, it can be concluded that safety awareness, safety monitoring system, roof weakness, ventilation system, fire-fighting system, and rock bolt quality are dominant in the entire project. The safety grade of the entire system is Grade III.

\section{Risk Control Measures}

According to the risk analysis result, in the analysis of Lugou Mine's three-soft coal seam outburst roof stability, the following five major risks have the highest probability of occurrence, including ventilation risks, safety monitoring risks, roof own risks, safety management risks, and firefighting risks, which have become the key control objects for Lugou Mine's three-soft coal seam outburst roof stability. In order to reduce coal seam risks and ensure the smooth completion of the project, attention should be focused on risk prevention from the following aspects. Corresponding control measures have been formulated.

(1) Ventilation Risks. The gas in the coal mine will continuously overflow. When the gas accumulates to a certain concentration, it will burn and explode in the fire source. In order to ensure the safety of the coal mine, the ventilation issue is particularly crucial.

(i) During the extraction period, the air distribution on the working face should not be less than $1500 \mathrm{~m}^{3} / \mathrm{min}$. The ventilation system is independent and the return air side is unblocked. The inlet and return air does not pass through the goaf or roof falling area. At the same time, the wind measurement should be strengthened and the personnel should be fixed.

(ii) If the gas exceeds the limit, the power supply of all nonintrinsically safe electrical equipment in No. 32081 working face as well as the upper and lower suballeys can be disconnected; the poweroff is sensitive and reliable. A total of 2 feed sensors are installed on the load side of the controlled switch, which is maintained by a dedicated person every day. The sensors are portable for comparison. The calibration is performed every 15 days with a full-time gas inspector.

(iii) Set up backup power supply and ventilator: when one power supply stops working or the ventilator fails, the backup power supply or the ventilator can be quickly used to ensure the normal ventilation in tunnels.

(2) Safety Monitoring Risks. The most important thing of safety monitoring is to control the gas limit and prevent gas accumulation. During the construction, when the gas concentration is detected to exceed the limit, the gas monitoring system will automatically cut off the power supply in the overlimit area, and the system can still work normally. At this time, measures should be taken to deal with the situation in accordance with the data provided by the system.

(i) It is strictly forbidden to allow people to enter the overlimit area. The variable air volume supply is used to control the air intake, and the gas in the overlimit area is discharged gradually.

(ii) When the gas is discharged, it is necessary to ensure that the gas concentration in the working 
area does not exceed the limit. Moreover, it should be ensured that the gas discharged from the coal mine does not exceed the limit. The gas inspectors must frequently inspect the gas concentration in the return air flow. When the gas concentration is less than $0.75 \%$, the air supply should be reduced.

(iii) After the normal ventilation is restored, the electromechanical equipment in the power-off area shall be inspected first. The power supply can be manually restored for normal construction only after the equipment is confirmed to be in good condition.

(3) Construction Personnel Risks. The main construction personnel risks in this project refer to the personnel physical condition and professional competence, as well as the safety awareness.

(i) Conduct safety education and training regularly. Safety education training can improve people's safety production knowledge and enhance their safety awareness, which can effectively prevent from unsafe behaviors.

(ii) Safety education training must be comprehensive with prominent focus and strong systemicity.

(iii) Conduct physical examinations on employees regularly.

(4) Fire-Fighting Risks.

(i) After the fire report is received, the on-site team leader and technical person in charge should first cut off the power supply and actively organize personnel to extinguish the fire. When the on-site personnel are threatened by disasters, they should be organized to evacuate in time in accordance with the gas combustion accident plan.

(ii) In the process of fire-fighting and disaster relief, the concentration, wind direction, and air volume of various toxic and harmful gases should be detected in time. Safety measures should be taken to prevent gas and coal dust explosion, as well as personnel poisoning timely when the situation is identified.

(iii) The electrical equipment should be inspected frequently to avoid electrical sparks, thus ensuring the continuous normal operation of the mechanical equipment and avoiding friction sparks.

\section{Conclusions}

Based on the engineering background of stability assessments of three-soft coal seam roof outburst coal seams, this paper used the fuzzy analytic hierarchy process combining the analytic hierarchy process and the fuzzy mathematics to conduct risk analysis of Lugou Mine's No. 32141 working face. It built an analytic hierarchy model. The influencing factors of primary and secondary indicators were determined and ranked by scores. The conclusions are as follows:
(1) The analytic hierarchy process is a method combining human subjective judgment and quantitative calculation. It has the characteristics of systematization and hierarchicalization. The quantitative information needed for the analysis is relatively less; the fuzzy mathematics evaluation method combines the fuzzy transformation principle and the maximum membership principle. The comprehensive evaluation of all factors related to the thing to be evaluated focuses on all relevant factors considered.

The fuzzy analytic hierarchy process is a combination of the analytic hierarchy process and the fuzzy mathematics method. It has the advantages of qualitative analysis and quantitative evaluation, which is a new method of evaluating coal seam roof. It can obtain a high accuracy of three-soft coal seam roof stability assessments.

(2) Based on the characteristics of the coal seams of the Lugou Mine, combined with historical data and after discussions with experts, the risks in each layer are divided into five categories: geological environment risks, safety management risks, roof own risks, safety facility risks, and construction personnel risks. Each category contains several basic risk factors. The analytic hierarchy process can be used to solve the weight of each factor. It can be concluded that safety awareness, safety monitoring system, roof weakness, ventilation system, fire-fighting system, rock bolt quality, and other risk factors dominate the entire project.

(3) After the analytic hierarchy process was used to obtain the weight of each risk factor, based on the fuzzy mathematics analysis, it is concluded that the safety grade of Lugou Mine's three-soft coal seam outburst roof stability is Grade III: "average." The main risks and harmful factors include ventilation risks, safety monitoring risks, roof own risks, safety management risks, and firefighting risks.

(4) According to the conclusion drawn from the fuzzy analytic hierarchy process, corresponding measures are proposed for factors with high risks, such as ventilation problems, safety monitoring systems, and safety management, to reduce the probability of accidents and ensure the safe production of coal mines. The fuzzy analytic hierarchy process can also be used to evaluate the stability of deep roof in other similar coal mines to reduce the probability of coal mine accidents.

\section{Data Availability}

The data used to support the findings of this study are available from the corresponding author upon request.

\section{Conflicts of Interest}

The authors declare that they have no conflicts of interest. 


\section{Acknowledgments}

This study was supported by the Postdoctoral Innovation Project of Hebei Province (no. B2019005005), Key Project of Hubei Provincial Department of Education (no. D20201506), Wuhan Institute of Technology Science Fund (no. K201855), and Guiding Project of Hubei Provincial Department of Education (no. B2020056).

\section{References}

[1] H. Zhang, Study on Fracture Evolution Law of Underground Coal and Rock under Protective Layer Mining in "Three Soft" Coal Seam, Qingdao Technological University, ShanDong, China, 2018.

[2] G. H. Zhang, R. Z. Miao, H. B. Liu et al., "Practice of fully mechanized top coal caving technology in three soft unstable thick seam," Zhongzhou Coal, vol. 45, no. 11, pp. 28-29, 2014.

[3] H. Y. Wang, B. Tan, Z. Z. Shao, Y. Guo, Z. Zhang, and C. Xu, "Influence of different content of $\mathrm{FeS}_{2}$ on spontaneous combustion characteristics of coal," Fuel, vol. 288, Article ID 119582, 2021.

[4] H. Wang, X. Fang, F. Du et al., "Three-dimensional distribution and oxidation degree analysis of coal gangue dump fire area: a case study," Science of The Total Environment, vol. 772, Article ID 145606, 2021.

[5] J. H. Shi, Study on the Support Technology of Roadway Effected by Sliding Geological Structure in Three-Soft Coal Seam of Gaocheng Coal Mine, China University of mining and technology, Xuzhou, China, 2014.

[6] B. Shu, X. P. Xie, Y. H. Guan et al., "Numerical simulation analysis of the roadway in the "three soft" coal seam," Shandong Industrial Technology, vol. 37, no. 3, p. 77, 2018.

[7] S. Guo, "Study on regional outburst prevention technology of three soft outburst coal seam," Zhongzhou Coal, vol. 31, no. 4, pp. 82-108, 2010.

[8] L. L. Xu and Q. G. Hu, "Supports stability analysis of long wall caving mining in "three soft", High Inclined Seam, Coal Technology, vol. 39, no. 8, pp. 24-26, 2020.

[9] L. Wang and Z. Y. Sa, "Coal technology "three soft" coal seam gas drilling along the seam drainage research," Technology Wind, vol. 21, p. 121, 2019.

[10] X. Chen and B. Xu, "Selection and application of gas control scheme in three soft coal seam with high outburst and large dip angle," Inner Mongolia Coal Economy, vol. 38, no. 8, pp. 22-23, 2020.

[11] P. J. M. Laarhoven and W. Pedrycz, "A fuzzy ex-tension of saaty's priority theory," Fuzzy Sets and Systems, vol. 11, no. 1-3, pp. 229-241, 1983.

[12] T. Chen and H. C. Wu, "fuzzy collaborative intelligence fuzzy analytic hierarchy process approach for selecting suitable three-dimensional printers," Soft Computing, vol. 25, pp. 4121-4134, 2020.

[13] X. M. Wang, J. H. Li, X. L. Zhang et al., "Optimizing mining stope structural parameters using a FAHP," Journal of China University of Mining \& Technology, vol. 39, no. 2, pp. 163-168, 2010.

[14] G. F. Song, W. D. Pan, J. H. Yang et al., "Mining methods selection in thick coal seam based on fuzzy analytic ierarchy process," Journal of Mining \& Safety Engineering, vol. 32, no. 1, pp. 35-41, 2015.

[15] P. Sridhar and S. Ganapuram, "Morphometric analysis using fuzzy analytical hierarchy process (FAHP) and geographic information systems (GIS) for the prioritization of watersheds," Arabian Journal of Geosciences, vol. 14, no. 4, pp. 1-29, 2021.

[16] Y. Peyman, Z. Hasan, I. D. Wolf, M. Karami, and S. Amiriyan, "Earthquake risk assessment using an integrated fuzzy analytic hierarchy process with artificial neural networks based on gis: a case study of Sanandaj in Iran," International Journal of Disaster Risk, vol. 50, Article ID 1010705, 2020.

[17] S. H. Zhou, J. K. Xing, Y. Q. Zhang et al., "An assessment model based on the hierarchical fuzzy analysis process for the bedding slope with the prestressed anchor cable frame reinforcement," Journal of Safety and Environment, vol. 20, no. 5, pp. 1695-1704, 2020.

[18] M. Ince, A. H. Isik, and T. Yigit, "Multi-Criteria approach to learning object selection through fuzzy AHP," MultipleValued Logic and Soft Computing, vol. 27, no. 1, pp. 47-62, 2016.

[19] J. Mallick, R. A. Khan, M. Ahmed et al., "Modeling groundwater potential zone in a semi-arid region of aseer using fuzzy-AHP and geoinformation techniques," Water, vol. 11, no. 12, p. 2656, 2019.

[20] M. Ahmed, M. N. Qureshi, J. Mallick, and N. Ben Kahla, "Selection of sustainable supplementary concrete materials using OSM-AHP-TOPSIS approach," Advances in Materials Science and Engineering, vol. 2019, Article ID 2850480, 12 pages, 2019.

[21] B. D. Rouyendegh, A. Oztekin, J. Ekong, and A. Dag, "Measuring the efficiency of hospitals: a fully-ranking DEA-FAHP approach," Annals of Operations Research, vol. 278, no. 1-2, pp. 361-378, 2019.

[22] S. Wijitkosum and T. Sriburi, "Fuzzy AHP integrated with GIS analyses for drought risk assessment: a case study from upper phetchaburi river basin," Water, vol. 11, no. 5, p. 939, 2019.

[23] Z. J. Wang, N. Wang, Z. Li et al., "Study on influence of tunnel construction on groundwater environment using fuzzy analytic hierarchy process," Railway Engineering, vol. 57, no. 11, pp. 80-83, 2016.

[24] D. D. Zhang, J. Q. Shen, P. F. Liu, Q. Zhang, and F. Sun, "Use of fuzzy analytic hierarchy process and environmental gini coefficient for allocation of regional flood drainage rights," International Journal of Environmental Research and Public Health, vol. 17, no. 6, p. 2063, 2020.

[25] J. R. Ribas, M. E. Arce, F. A. Sohler, and A. Suárez-García, "Data and calculation approach of the fuzzy AHP risk assessment of a large hydroelectric project," Data in Brief, vol. 25, Article ID 104294, 2019.

[26] T. Wu, X. Wei, Q. W. Zhong et al., "Analysis and control of construction risk by PBA to metro station based on fuzzy analytic hierarchy process," Jiangsu Construction, vol. 41, no. 1, pp. 86-89, 2021.

[27] T. Liang, "Research on risk evaluation of highway cost based on fuzzy analytic hierarchy process," Engineering and Technological Research, vol. 6, no. 1, pp. 23-24, 2021.

[28] X. Y. Li, "An application of fuzzy analytic hierarchy process in the evaluation of dressing method of ningqiang manganese ore," China's Manganese Industry, vol. 38, no. 6, pp. 37-40, 2020.

[29] M. Zhang, L. Cui, W. Hu, J. Du, Z. Zhang, and C. Wang, "Acoustic emission experimental research of the damage characteristics of raw coal under different loading and unloading rates," Shock and Vibration, vol. 2020, Article ID 9063929, 15 pages, 2020.

[30] L. Bai, H. Wang, C. Shi, Q. Du, and Y. Li, “Assessment of SIP buildings for sustainable development in rural China using 
AHP-grey correlation analysis," International Journal of Environmental Research and Public Health, vol. 14, no. 11, p. 1292, 2017.

[31] Environmental Research, "Findings on environmental research discussed by investigators at Tongji university (the application of fuzzy mathematics method in evalution for water quality of Xijiu river, China)," Ecology Environment \& Conservation, vol. 23, p. 260, 2017.

[32] A. Hosein, H. V. Abdollah, A. Aref, and A. Moslehi, "Revisiting the approximated weight extraction methods in fuzzy analytic hierarchy process," International Journal of Intelligent Systems, vol. 36, no. 4, pp. 1644-1667, 2020.

[33] D. J. Wu, F. B. Zhou, and X. M. Qian, "Comprehensive evaluation method of fuzzy mathematics for safety unsealing in fire area," Journal of Mining \& Safety Engineering, vol. 28, no. 1, pp. 56-60, 2011.

[34] S. Z. Zheng, B. Z. Chen, and Y. J. Liu, "Fire risk assessment and countermeasure of enterprises," Industrial Safety and Environmental Protection, vol. 27, no. 10, pp. 30-32, 2001. 